\title{
Heat stress and strain limits applicable to military helicopter aircrew
}

\author{
Andy Weller", Jonathan Boyd, Ken Puxley \\ From 15th International Conference on Environmental Ergonomics (ICEE XV) \\ Portsmouth, UK. 28 June - 3 July 2015
}

\section{Introduction}

Heat stress can result in uncompensated heat storage (termed heat strain and indicated by core temperature, $T_{C}$ ), heat illness, impaired performance and fatigue, and represents a significant threat to the effectiveness of aircrew undertaking hot-weather operations. To determine the potential risk to aircrew, two physiological aircrew simulation trials $(1 \& 2)$ were undertaken to assess the environmental heat stress resulting in a mean $T_{C}$ of $38{ }^{\circ} \mathrm{C}$ (occupational limit [e.g. 1]), and the level of parallel heat strain variables.

\section{Methods}

In Trial 1, 16 unacclimatised men undertook $4 \times 170$ minute heat tests in a thermal chamber controlled at wet-bulb-globe-temperatures (WBGTs) of 18, 22, 27 and $31{ }^{\circ} \mathrm{C}$ wearing a representative aircrew clothing and equipment ensemble (including body armour). The volunteers were assigned to two groups of 8 , with one group completing an exercise protocol representative of the metabolic cost of helicopter pilots (Front) and the other undertook a rear crew simulation (Rear) (metabolic rate 95 and $117 \mathrm{~W} . \mathrm{m}^{-2}$, respectively). In Trial 2, 8 different men completed the heat test at a WBGT of $28.5{ }^{\circ} \mathrm{C}$. Physiological (rectal temperature, $T_{R E}$; mean skin temperature, $T_{S K}$; total rate of mass loss, $M_{T O T}$; heart rate, $H R$ ), and subjective indicators (thermal sensation, TS; thermal comfort, $T C$ ) of heat strain were obtained in both trials.

\section{Results}

Mean heat strain responses at 170 minutes in the different thermal environments for Front are given in Table 1. The responses were generally not different between Front and Rear.

\section{Discussion}

There was a general curvilinear relationship between WBGT and the heat strain responses. The $38{ }^{\circ} \mathrm{C} T_{C}$ limit was reached at 165 minutes in the $28.5^{\circ} \mathrm{C}$ environment and the corresponding increase in $H R$ was consistent with the physiological limit in ISO 9886 [1]. It

Table $\mathbf{1}$ Mean heat strain responses in the $\mathbf{5}$ thermal environments

\begin{tabular}{|c|c|c|c|c|c|}
\hline Variable / WBGT $\left({ }^{\circ} \mathrm{C}\right)$ & 18 & 22 & 27 & 28.5 & 31 \\
\hline$T_{R E}\left({ }^{\circ} \mathrm{C}\right)$ & 37.5 & $37.4^{\mathrm{ns}}$ & $37.7^{\# \#}$ & $38.1^{\S}$ & $38.5^{*}$ \\
\hline$T_{S K}\left({ }^{\circ} \mathrm{C}\right)$ & 34.1 & $35.2^{\Delta \Delta}$ & $36.4^{\# \#}$ & $37.4^{\S \S}$ & $37.3^{\text {ns }}$ \\
\hline$M_{\text {TOT }}\left(\mathrm{kg} \cdot \mathrm{h}^{-1}\right)$ & 0.2 & $0.3^{\Delta}$ & $0.4^{\#}$ & $0.6^{\S \S}$ & $0.7^{\mathrm{ns}}$ \\
\hline$H R / \uparrow H R$ [vs WBGT 18] (b.min $\left.{ }^{-1}\right)$ & $88 / 0$ & $91^{\text {ns }} / 3^{\text {ns }}$ & $103 / 14^{\# \#}$ & $118 / 30^{\S}$ & $129 / 41^{\text {ns }}(p=0.08)$ \\
\hline$T S^{1} / T C^{2}$ & $1.1 / 0.5$ & $1.4^{\mathrm{ns}} / 0.8^{\mathrm{ns}}$ & $2.1^{\#} / 0.9^{\text {ns }}$ & $3.0^{\S} / 2.1^{\S \S}$ & $3.3^{\text {ns }} / 2.1^{\text {ns }}$ \\
\hline
\end{tabular}

${ }^{1}$ Thermal Sensation (TS) ratings: 0 (Neutral), 1 (Slightly Warm), 2 (Warm), 3 (Hot), 4 (Very Hot). ${ }^{2}$ Thermal Comfort (TC) ratings: 0 (Comfortable), 1 (Slightly Uncomfortable), 2 (Uncomfortable), 3 (Very Uncomfortable), 4 (Exceedingly Uncomfortable). Statistical differences between WBGT 18 and $22\left({ }^{\Delta}\right), 22$ and $27(\#)$, 27 and $28.5\left(\left(^{\S}\right)\right.$ and 28.5 and $31\left(^{*}\right)$ are given by single $(P<0.05)$ and double $(P<0.01)$ symbols (Students t tests). ${ }^{\text {ns }}$ signifies no statistical difference.

\footnotetext{
* Correspondence: asweller@QinetiQ.com

Aircrew Systems, QinetiQ, Cody Technology Park, Ively Road, Farnborough,
}

GU14 OLX, UK 
remains to be established whether the subjective thermal strain experienced at a WBGT of $28.5{ }^{\circ} \mathrm{C}$ (partly driven by high $\mathrm{T}_{\mathrm{SK}}$ ) could influence performance.

\section{Conclusion}

Helicopter aircrew are likely to exceed the $T_{C}$ limit of $38{ }^{\circ} \mathrm{C}$ and be at risk of heat-related illness and impaired performance when exposed to a cockpit/cabin WBGT of $\sim 28^{\circ} \mathrm{C}$ and beyond.

\section{Acknowledgements}

This work was undertaken as part of the Aircrew Systems Research programme and was funded by the UK MOD.

Published: 14 September 2015

\section{Reference}

1. ISO $9886: 2004$ Ergonomics - Evaluation of thermal strain by physiological measurements. International Standards Institution. Geneva, Switzerland. Also published as BS EN ISO 9886:2004 (BSI, UK).

doi:10.1186/2046-7648-4-S1-A26

Cite this article as: Weller et al:: Heat stress and strain limits applicable

to military helicopter aircrew. Extreme Physiology \& Medicine 2015

4(Suppl 1):A26.

Submit your next manuscript to BioMed Central and take full advantage of:

- Convenient online submission

- Thorough peer review

- No space constraints or color figure charges

- Immediate publication on acceptance

- Inclusion in PubMed, CAS, Scopus and Google Scholar

- Research which is freely available for redistribution

Submit your manuscript at www.biomedcentral.com/submit 